D.S. Sofronov, E.M. Sofronova, N.O. Kovalenko, V.V. Starikov, A.S. Gerasimenko, V.N. Baumer, A.M. Lebedinsky, P.V. Matejchenko, E.V. Grishina, S.N. Lavrynenko and A.G. Mamalis

\title{
Obtaining a ZnSe furnace charge from aqueous solution
}

\begin{abstract}
The influence of synthesis conditions on the process of obtaining a charge of zinc selenide from alkaline solutions via the interaction of zinc with selenium and zinc oxide with selenium in the presence of a reducing agent is reported. It is shown that the interaction of zinc and selenium in alkaline solution and the $\mathrm{ZnSe}$ output increases with increasing concentration of alkali and synthesis time and reaches a maximum of about $85 \mathrm{wt} \%$ in 15 molar $\mathrm{NaOH}$ after 2 hours, resulting in the formation of $0.1-0.3 \mu \mathrm{m}$ spherical particles. The use of hydrazine hydrate can increase $\mathrm{ZnSe}$ output up to $97 \mathrm{wt} \%$. The powder is formed in spherical agglomerates with an average size of $0.5 \mu \mathrm{m}$. The main impurity phases are oxide, carbonate and zinc hydroxide, which are removed during vacuum heat treatment at $800-900{ }^{\circ} \mathrm{C}$ for 1 hour.
\end{abstract}

Keywords: optical components, particles, powder for growing crystals, sensors, solar energy converters

Nanotechnology Perceptions 10 (2014) 154-163 